\title{
Synthesis, Characterization and Antibacterial Application of Copolymers Based on $N, N$-Dimethyl Acrylamide and Acrylic Acid
}

\author{
Ulantay Nakan ${ }^{1, *}$, Shayahati Bieerkehazhi ${ }^{2} \mathbb{D}$, Balgyn Tolkyn ${ }^{3}$, Grigoriy A. Mun ${ }^{4}$, Mukhit Assanov ${ }^{4}$, \\ Merey E. Nursultanov ${ }^{1}$, Raikhan K. Rakhmetullayeva ${ }^{4}$, Kainaubek Toshtay ${ }^{4}$, El-Sayed Negim ${ }^{5}$ (D) \\ and Alibek Ydyrys ${ }^{6}$
}

check for updates

Citation: Nakan, U.; Bieerkehazhi, S. Tolkyn, B.; Mun, G.A.; Assanov, M.; Nursultanov, M.E.; Rakhmetullayeva, R.K.; Toshtay, K.; Negim, E.-S.; Ydyrys, A. Synthesis,

Characterization and Antibacterial Application of Copolymers Based on $N, N$-Dimethyl Acrylamide and Acrylic Acid. Materials 2021, 14, 6191. https://doi.org/10.3390/ma14206191

Academic Editor: Binyang Du

Received: 5 August 2021

Accepted: 9 October 2021

Published: 18 October 2021

Publisher's Note: MDPI stays neutral with regard to jurisdictional claims in published maps and institutional affiliations.

Copyright: (c) 2021 by the authors Licensee MDPI, Basel, Switzerland. This article is an open access article distributed under the terms and conditions of the Creative Commons Attribution (CC BY) license (https:// creativecommons.org/licenses/by/ $4.0 /)$.
1 Institute of Geology and Oil \& Gas Business, Satbayev University, Almaty 050013, Kazakhstan; merey1980@mail.ru

2 Ross Tilley Burn Centre, Sunnybrook Health Sciences Centre, University of Toronto, Toronto, ON M5S 1A1, Canada; sayahat2017@gmail.com

3 A.B. Bekturov Institute of Chemical Sciences, Street Ualihanov106, Almaty 050010, Kazakhstan; balgn-888@mail.ru

4 Al-Farabi Kazakh National University, Almaty 050012, Kazakhstan; mun-grig@yandex.ru (G.A.M.); muhit777.82@mail.ru (M.A.); raichan-rach@mail.ru (R.K.R.); kainaubek.toshtay@gmail.com (K.T.)

5 Laboratory of Advanced Materials and Technology, Kazakh-British Technical University, 59 Tole bi St., Almaty 050000, Kazakhstan; elashmawi5@yahoo.com

6 Biomedical Research Centre, Al-Farabi Kazakh National University, al-Farabi 71, Almaty 050040, Kazakhstan; ydyrys.alibek@gmail.com

* Correspondence: ulantaynakan@gmail.com; Tel.: +7-701-165-89-36

\begin{abstract}
Hydrogel copolymers based on $N, N$-dimethyl acrylamide (DMA) and acrylic acid (AAc) were synthesized using a solution polymerization technique with different monomer ratios and ammonium persulfate as an initiator. This paper investigates the thermal stability, physical and chemical properties of the hydrogel copolymer. Testing includes Fourier transform infrared spectroscopy (FTIR), thermogravimetric analysis (TGA), scanning electron microscopy (SEM) and elemental analysis (CHNS). The copolymer composition was determined by elemental analysis, and the reactivity ratios of monomers were calculated through linearization methods such as Fineman-Ross (FR), inverted Fineman-Ross (IFR), Kelen-Tudos (KT) and Mayo-Lewis (ML). Good agreement was observed between the results of all four methods. The ratio of $r_{1}$ and $r_{2}$ were $0.38\left(r_{1}\right)$ and $1.45\left(r_{2}\right)(F R)$, $0.38\left(r_{1}\right)$ and $1.46\left(r_{2}\right)$ (IFR), $0.38\left(r_{1}\right)$ and $1.43\left(r_{2}\right)(K T)$, and $0.38\left(r_{1}\right)$ and $1.45\left(r_{2}\right)(\mathrm{ML})$. Hydrogel copolymers exhibited good thermal stability, and SEM showed three-dimensional porous structures. Antibiotic-free and antibiotic-loaded hydrogels demonstrated antimicrobial properties against both Gram-positive and Gram-negative bacteria. As the ratio of DMA in hydrogel copolymer increased, the activity of copolymer against bacteria enhanced. The results indicated that these hydrogels have the potential to be used as antibacterial materials.
\end{abstract}

Keywords: N,N-dimethyl acrylamide; acrylic acid; reactivity ratios; Fineman-Ross; inverted FinemanRoss; Kelen-Tudos; antibacterial activity

\section{Introduction}

Three-dimensional polymers with unique properties have shown great promise in the polymer industry, with potential applications including medical appliances in drug delivery, electronics, biotechnology, and the food industry. Stimuli-responsive hydrogels belong to a new and vital class of cross-linked polymers [1-5].

Poly ( $N$-isopropyl acrylamide)-based stimuli-responsive copolymers demonstrate great potential in biomedical applications. Poly( $N$-isopropyl acrylamide) affords phase separation caused by reversible hydration transition in aqueous solutions with temperatures 
higher than $32{ }^{\circ} \mathrm{C}$. Polymers with similar remarkable capabilities include copolymers based on $\mathrm{N}, \mathrm{N}$-diethyl acrylamide, $\mathrm{N}, \mathrm{N}$-dimethyl acrylamide and $\mathrm{N}$-vinyl caprolactam monomers. $\mathrm{N}, \mathrm{N}$-dimethyl acrylamide based hydrogels have gained significant attention due to their potential for many different applications. Studies on DMA based copolymers have reported excellent characteristics. However, the mechanical strength of these synthesized hydrogels is weak [6-9].

The copolymer composition and reactivity ratios of the monomer are crucial in evaluating copolymer specific applications. The reactivity monomer ratios calculated by conventional linear methods are not always accurate, but several non-linear ways have been developed to assess their value $[10,11]$.

Polymers and polymer-based materials are not only widely used in the biomedical field, and they are also receiving more attention in food science and other technologies as well $[12,13]$. One of the crucial positions in the medical field is the antibacterial actions of the materials used in medicine, since bacterial growth must be prevented on medical devices, such as prosthetic materials, surgical masks, etc. In addition, the antibacterial functions are more desirable for preserving food quality and water sanitations as well.

Our lab prepared water swelling and soluble thermosensitive copolymer poly $(\mathrm{N}$ isopropyl acrylamide-co-2-hydroxyl ethyl acrylate) and various physical and chemical methods have studied their different characteristics. Linear copolymer composition and reactivity monomer ratios were calculated by Kelen-Tudos and Fineman-Ross methods [14-17].

In this study, poly(DMA-co-AAc) hydrogels were synthesized by free-radical copolymerization. These hydrogels were characterized by CHN, FTIR, TGA, and SEM. In addition, the monomer reactivity ratios of DMA and AAc were determined via using Fineman-Ross (FR), inverted Fineman-Ross (IFR), Mayo-Lewis (ML) and Kelen-Tudos (KT) methods. Several biological tests were performed to determine these hydrogels antibacterial features and drug delivery capabilities.

\section{Materials and Methods}

\subsection{Materials}

Acrylic acid (AAc) stabilized with hydroquinone with a purity of $99.5 \%$ extra pure (CAS 79-10-7) was supplied by Acros Organics (Geel, Belgium). N,N-dimethyl acrylamide (DMA, 99\%), ammonium persulfate (98\%, APS, CAS 7727-54-0), and $\mathrm{N}, \mathrm{N}$-methylene-bisacrylamide (99\%, CAS 110-26-9) were obtained from Sigma-Aldrich (Heidelberg, Germany). Furthermore, the gentamicin of clinical grades was obtained from Kazakhstan in the specification of $1 \mathrm{~mL}: 40$ units (Shymkent, Kazakhstan, $40 \mathrm{mg} / \mathrm{mL}$ ). In addition, several types of bacterial culture were obtained from the laboratory.

\subsection{Synthesis of Copolymers}

Hydrogels based on DMA and AAc were synthesized with composition ratios (M1:30/70, M2: 40/60, M3: 50/50, M4: 60/40, M5: 70/30), by free radical solution (water) polymerization technique with ammonium persulfate $\left(2 \times 10^{-2} \mathrm{M}\right)$ as the initiator and $N, N$-methylenebis-acrylamide ( $0.1 \mathrm{~mol} . \%$ ) as the cross-linking agent. Monomer mixture accounts for 30\% of the total volume, and the rest belongs to the water. The total volume of the reaction mixture was maintained at $10 \mathrm{~mL}$ for all the compositions. The resulting mixture was poured into the glass ampoule and saturated with argon for $10 \mathrm{~min}$ to remove oxygen. Then the copolymerization was performed in hermetically sealed glass ampoules at $60^{\circ} \mathrm{C}$ for $20 \mathrm{~min}$. The obtained hydrogels were washed with distilled water for 10 days to clean the samples from unreacted monomers. Then, the hydrogel samples were dehydrated at room temperature and in a vacuum oven until the weight was kept constant [15].

\subsection{Instrumentation and Methods}

Fourier transforms infrared spectrophotometer (FTIR) IR Nicolet 5700 spectrometer was used to analyze chemical structures of poly(DMA-co-AAc) copolymers in the 
$400-4000 \mathrm{~cm}^{-1}$ wavenumber range. The dried and grounded (until suitable sized powder) hydrogel samples mixed with standard $\mathrm{KBr}$ powder were compressed into a pellet for the test.

To describe the composition of poly(DMA-co-AAc) copolymer by elemental analysis method, the dried hydrogel samples were carried out using 2400 CHNS/O Series II System by Perkin Elmer elemental carbon, hydrogen, nitrogen and sulfur components in the samples were measured by weight percentage.

Hydrogels thermal properties were determined by thermogravimetric analysis (TGA) between 30 and $600{ }^{\circ} \mathrm{C}$ with a $10^{\circ} \mathrm{C} / \mathrm{min}$ heating rate under nitrogen atmosphere on a Perkin Elmer Simultaneous Analyzer STA 6000 (PerkinElmer, Waltham, MA, USA).

The surface morphology of hydrogel was investigated by scanning electron microscopy (SEM), on JSM-6390LV, (JEOL, Tokyo, Japan), with an operating voltage of $20 \mathrm{kV}$. SEM images were obtained from the fractured surface of dried hydrogels.

\subsection{Monomer Reactivity Ratio}

The monomer reactivity ratios were determined by using the Fineman-Ross (FR), inverted Fineman-Ross (IFR), Kelen-Tudos (KT) and Mayo-Lewis methods [18-21]. The equation for IFR is:

$$
\mathrm{G}=\mathrm{Hr}_{1}-\mathrm{r}_{2}
$$

$r_{1}$ and $r_{2}$ were calculated by plotting $G=F(f-1) / f$ versus the $H=F^{2} / f$ to obtain a straight line where the slope was the value for $\left(r_{1}\right)$ and the intercept was the value for $\left(-r_{2}\right)$. The values are shown in plots of IFR and FR.

For KT method, the equation is:

$$
\begin{gathered}
\eta=r_{1} \zeta-r_{2} / a(1-\zeta) \\
\text { Where, } \eta=G /(\alpha+H), \zeta=H /(\alpha+H), \alpha=\left(H_{\max } * H_{\text {min }}\right)^{1 / 2}
\end{gathered}
$$

$r_{1}$ and $r_{2}$ were calculated by plotting $\eta$ versus $\zeta$, and a straight-line was produced which gave $\left(-r_{2} / \alpha\right)$ and $\left(r_{1}\right)$. The values are shown in KT plot. For the Mayo-Lewis method, a plot was obtained by using the equation:

$$
r_{2}=F\left[1 / f\left(1+F r_{1}\right)-1\right]
$$

\subsection{Antibacterial Tests}

The antibacterial and drug delivery properties of the poly(DMA-co-AAc) hydrogels with different feed compositions were determined on nutrient agar. For this purpose, the obtained hydrogels were washed with distilled water for several days to remove unreacted monomers. Then, the hydrogel disks (diameter of 7-8 $\mathrm{mm}$ and height of $1 \mathrm{~mm}$ ) were dehydrated in a vacuum oven at room temperature until the weight remained constant. Two hydrogel disks from each of the M1, M3 and M5 hydrogels samples were cleaned and dried. One was immersed in a solution and the other was in an antibiotic solution (Gentamicin). All samples were stored at room temperature for $24 \mathrm{~h}$. The hydrogel disks retained their soft form, absorbing the necessary solutions.

We chose Staphylococcus aureus as the test organism, which is a Gram-positive (GP) bacterium. GP bacteria can be colored crystal violet due to a thick layer of peptidoglycan. In contrast, Gram-negative (GN) bacteria can be turned red or pink. A variety of inflammatory diseases, including skin inflammation, pneumonia, sepsis and other infections, can be caused by Staphylococcus aureus [15].

Antimicrobial tests of poly(DMA-co-AAc) hydrogels were studied using GP bacteria (Staphylococcus aureus ATCC 6538-p) and GN bacteria (E. coli (ATCC 25922) and P. aeruginosa (ATCC 9027)) using the disc diffusion method. The composition (for staphylococcus aureus) of the nutritional agar was as follows $(\mathrm{g} / \mathrm{L})$ : meat extract 1.5; sodium chloride 5, yeast extract 1.5; peptone 5; agar 15.0; $\mathrm{pH}$ 7.4-7.6. Incubation of test organisms with applied copolymers was carried out in the thermostat (Binder) at $37{ }^{\circ} \mathrm{C}$ for 24 and $48 \mathrm{~h}$. The 
antimicrobial activity of the hydrogels was determined by measuring the diameter (in $\mathrm{mm}$ ) of their inhibition zones to microorganisms' growth. Photo documents confirmed the results of the studies.

\section{Results and Discussion}

\subsection{FTIR Analysis of Poly (DMA-co-AAc) Hydrogel}

The infrared spectroscopy method was utilized to confirm the functional groups in the copolymers. Although FTIR is a conventional way of studying copolymers, it has not lost its relevance in modern research. Infrared spectroscopy was applied to confirm the structure of the poly(DMA-co-AAc) copolymer. The obtained copolymers were recorded on FTIR spectroscopy in 500-4000 $\mathrm{cm}^{-1}$ as shown in Figure 1. Peaks at 2924, 2848, 2908 and $2843 \mathrm{~cm}^{-1}$ for C-H groups (stretching, aliphatic), 1670, 1608, 1586, and $1548 \mathrm{~cm}^{-1}$ for group C-N $3500-3200 \mathrm{~cm}^{-1}, 1790 \mathrm{~cm}^{-1}$ for group $\mathrm{C}=\mathrm{O}$ (group ester), $3500-3200 \mathrm{~cm}^{-1}$ for $\mathrm{OH}$ group were recorded [22-24]. These signals expressed the structural formula of the poly(DMA-co-AAc).

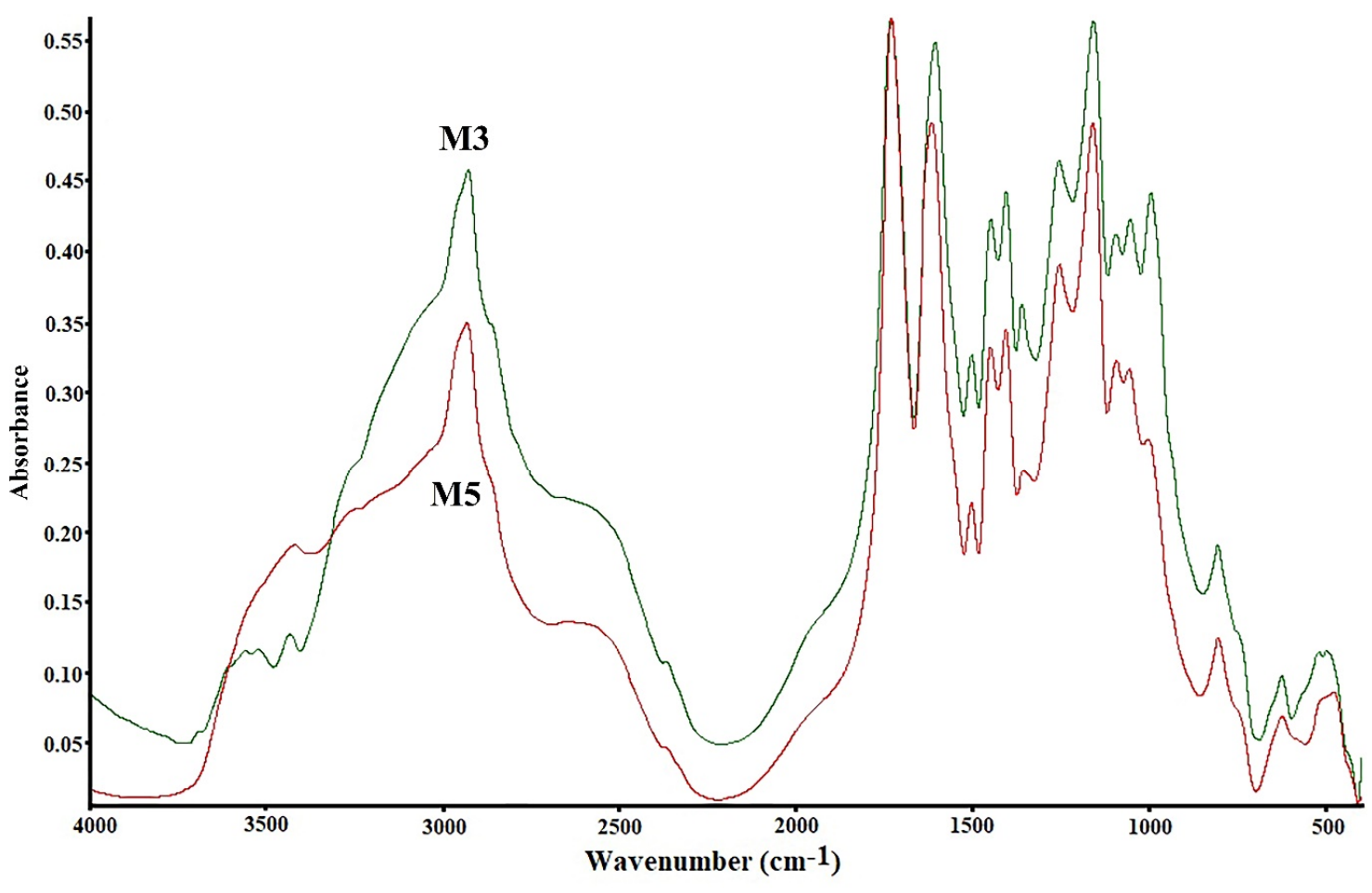

Figure 1. FTIR signals of hydrogels poly(DMA-co-AAc).

\subsection{Monomer Reactivity Ratio}

The copolymer composition is based on monomers and element feed. Therefore, it is essential to know monomers and radicals' reactivity in describing the polymerization process. Although the poly(DMA-co-AAc) hydrogels were obtained during the synthesis by the initial monomeric composition, the calculations were performed using element analysis results. One of the poly(DMA-co-AAc) copolymer features is the presence of nitrogen in a single monomer, which allows calculating the copolymer content through the proportion of nitrogen. Thus, we made calculations based on nitrogen. Table 1 shows the influence of the molar fraction of DMA in copolymer $\left(\mathrm{m}_{1}\right)$, the mole fraction of DMA monomer in $\left(\mathrm{M}_{1}\right)$ and nitrogen from elemental analysis. The reactivity ratio was investigated by using Fineman-Ross (FR), inverted Fineman-Ross (IFR), Kelen-Tudos (KT) and Mayo-Lewis methods. Table 1 shows the parameters of the FR, IFR and KT equations. The reactivity ratio for DMA $\left(\mathrm{r}_{1}\right)$ and AAc $\left(\mathrm{r}_{2}\right)$ from the FR and IFR plot (Figure 2), FT and ML (Figure 3) 
plot are given in Table 2. The molar fraction of the DMA in the copolymer versus its molar fraction in the feed is shown in Figure 4.

Table 1. Determination of copolymerization reactivity ratios of DMA $\left(r_{1}\right)$ and AAc $\left(r_{2}\right)$ systems by Fineman-Ross, inverted Fineman-Ross and Kelen-Tudos methods.

\begin{tabular}{|c|c|c|c|c|c|c|c|c|c|c|c|}
\hline \multirow[b]{2}{*}{ 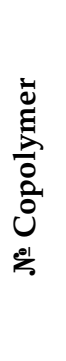 } & \multirow{2}{*}{ 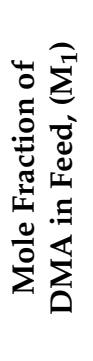 } & \multirow[b]{2}{*}{ 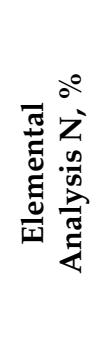 } & \multirow{2}{*}{ 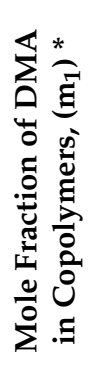 } & \multirow[b]{2}{*}{$\sum_{\substack{I \\
I}}^{N}$} & \multirow[b]{2}{*}{$\begin{array}{l}\mathcal{E} \\
\mathbb{E} \\
\Xi \\
\text { II }\end{array}$} & \multicolumn{2}{|c|}{ Fineman-Ross } & \multicolumn{2}{|c|}{ Kelen-Tudos } & \multicolumn{2}{|c|}{$\begin{array}{c}\text { Inverted } \\
\text { Fineman-Ross }\end{array}$} \\
\hline & & & & & & 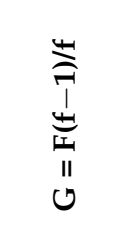 & $\begin{array}{l}\underset{\text { II }}{\stackrel{4}{I}} \\
\text { II }\end{array}$ & 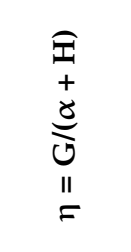 & 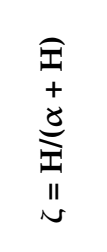 & $\mathrm{G} / \mathrm{H}$ & $1 / H$ \\
\hline M1 & 30 & 3.85 & 21 & 0.4286 & 0.2658 & -1.1839 & 0.6911 & -0.4885 & 0.2831 & -1.7131 & 1.4469 \\
\hline M2 & 40 & 4.93 & 28 & 0.6667 & 0.3889 & -1.0476 & 1.1429 & -0.3621 & 0.3945 & -0.9166 & 0.8749 \\
\hline M3 & 50 & 6.167 & 36 & 1 & 0.5625 & -0.778 & 1.778 & -0.2189 & 0.5029 & -0.4353 & 0.5647 \\
\hline M4 & 60 & 7.37 & 44 & 1.5 & 0.7857 & -0.4091 & 2.8636 & -0.089 & 0.6210 & -0.1429 & 0.3492 \\
\hline M5 & 70 & 8.71 & 54 & 2.3333 & 1.1739 & 0.3457 & 4.6378 & 0.0541 & 0.7261 & 0.0745 & 0.2156 \\
\hline
\end{tabular}

* Calculated from nitrogen $(\mathrm{N}, \%)$ results in copolymers. $\mathrm{A}=\left(\mathrm{H}_{\max }{ }^{*} \mathrm{H}_{\min }\right)^{1 / 2}=1.7499$.

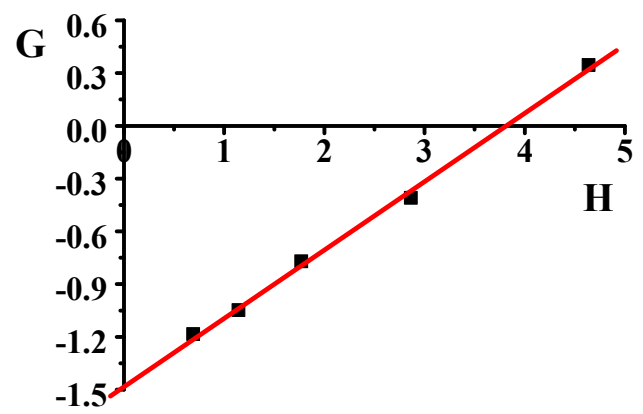

(a)

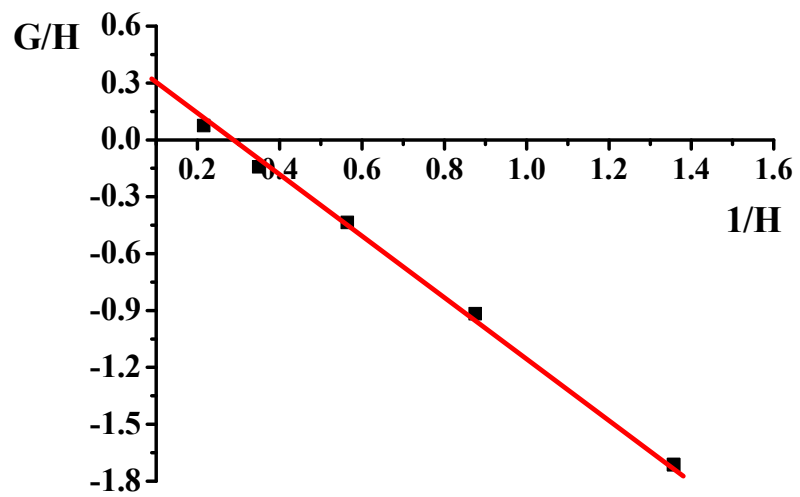

(b)

Figure 2. Fineman-Ross (a) and inverted Fineman-Ross (b) plots of poly(DMA-co-AAc).

Table 2. Copolymer constants based on Fineman-Ross, inverted Fineman-Ross, Kelen-Tudos and Mayo-Lewis methods.

\begin{tabular}{clccc}
\hline № & \multicolumn{1}{c}{ Methods } & $\mathbf{r}_{\mathbf{1}}$ & $\mathbf{r}_{\mathbf{2}}$ & $\mathbf{r}_{\mathbf{1}}{ }^{*} \mathbf{r}_{\mathbf{2}}$ \\
\hline 1 & Fineman-Ross (FR) & 0.38 & 1.45 & 0.55 \\
\hline 2 & Inverted Fineman-Ross (IFR) & 0.38 & 1.46 & 0.55 \\
\hline 3 & Kelen-Tudos (KT) & 0.38 & 1.43 & 0.54 \\
\hline 4 & Mayo-Lewis & 0.38 & 1.45 & 0.57 \\
\hline
\end{tabular}

KT, IFR, FR and ML calculations showed that the values of $r_{1}$ and $r_{2}$ obtained by these methods were associated with each other and were based on the composition diagram copolymer and the presence of $r_{1}<1$ and $r_{2}>1$. Under the influence of polar and spatial factors in the monomer and radical, i.e., the product of constants is less than one $\left(r_{1}^{*} r_{2}<1\right)$, which follows the monomer links of AAc and DMA tend to alternate in the chain 


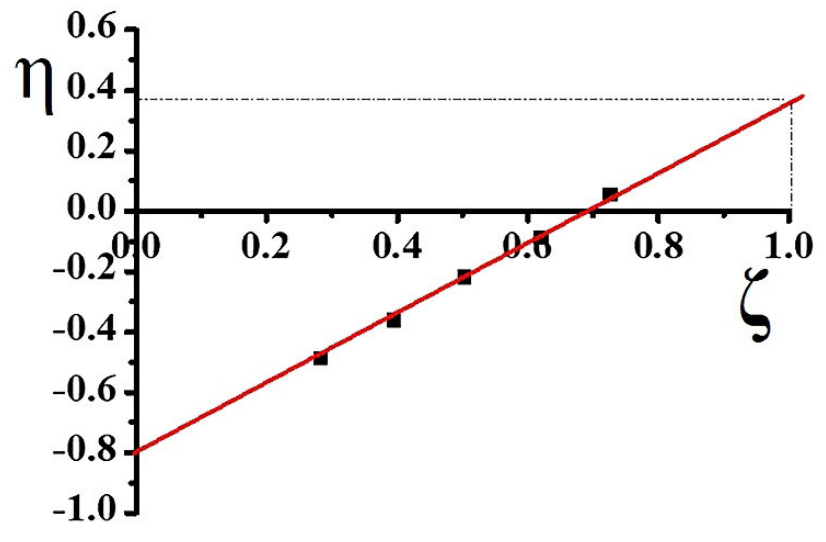

(a)

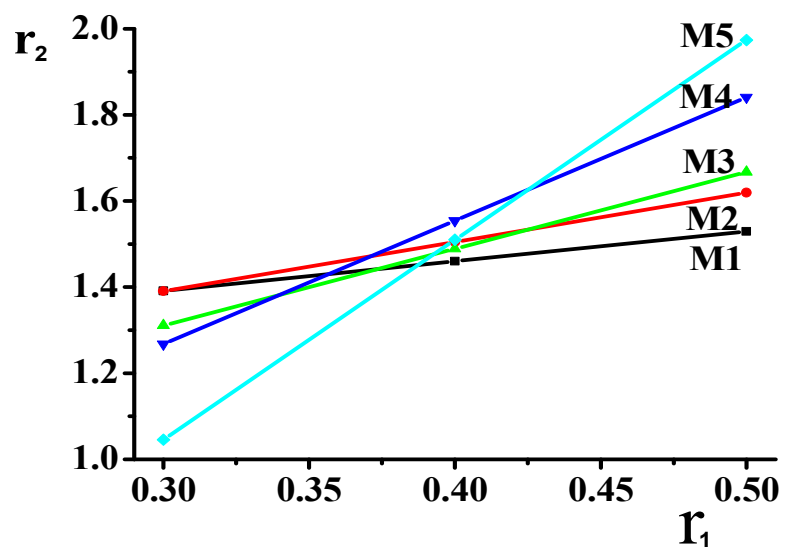

(b)

Figure 3. Kelen-Tudos (a) and Mayo-Lewis (b) plot of poly(DMA-co-AAc) copolymer.

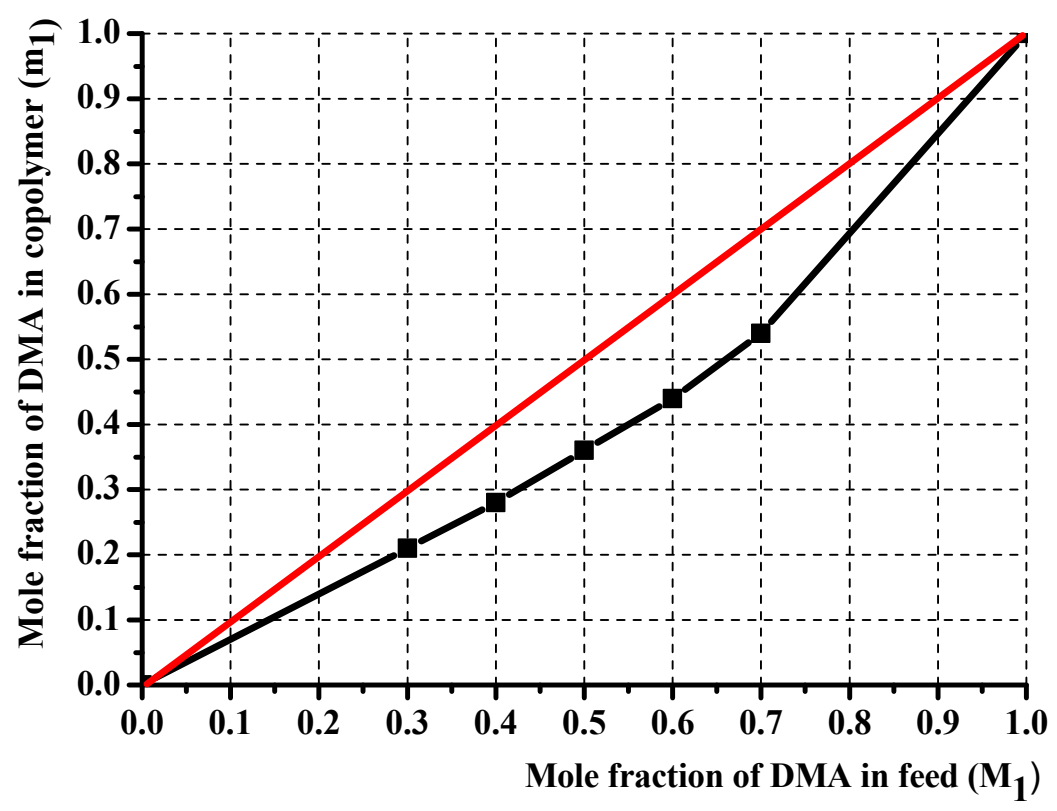

Figure 4. Composition of poly(DMA-co-AAc) copolymer.

\subsection{Thermogravimetric Analyses (TGA)}

Thermal stability and the DMA ratio affecting the weight loss in hydrogels were investigated by TGA/DTG at $29-594{ }^{\circ} \mathrm{C}$ with $\mathrm{N}_{2}$ in the inert atmosphere. TGA thermogram for poly(DMA-Co-AAc) hydrogels (M3 and M5) are shown in Figure 5 and Table 3. The thermal degradation for copolymers (M3 and M5) proceeds in three stages. The first weight loss (12.576 wt \%) occurred between 29 and $160{ }^{\circ} \mathrm{C}$ for $\mathrm{M} 3,(6.76$ wt \%) was between 30.24 and $209.6{ }^{\circ} \mathrm{C}$ for M5 to removing water and moisture. Furthermore, the weight loss increased from $6 \%$ to $12 \%$, increasing the ratio of AAc from $30 \%$ to $50 \%$ in the copolymer, indicating that polyacrylic acid (PAAc) hydrogels could absorb a large amount of water without dissolving [25]. The second and third stages occurred between $160.31^{\circ} \mathrm{C}$ and $594{ }^{\circ} \mathrm{C}$ for M3 and between 209.6 and $594.5^{\circ} \mathrm{C}$ for M5, which was related to the decomposition with losing carboxyl, amid and hydroxyl groups in the copolymers. Thermal stability and initial degradation temperature were at $380^{\circ} \mathrm{C}$, as shown by DTG, demonstrating the stable characteristic of the poly(DMA-co-AAc) copolymers. 


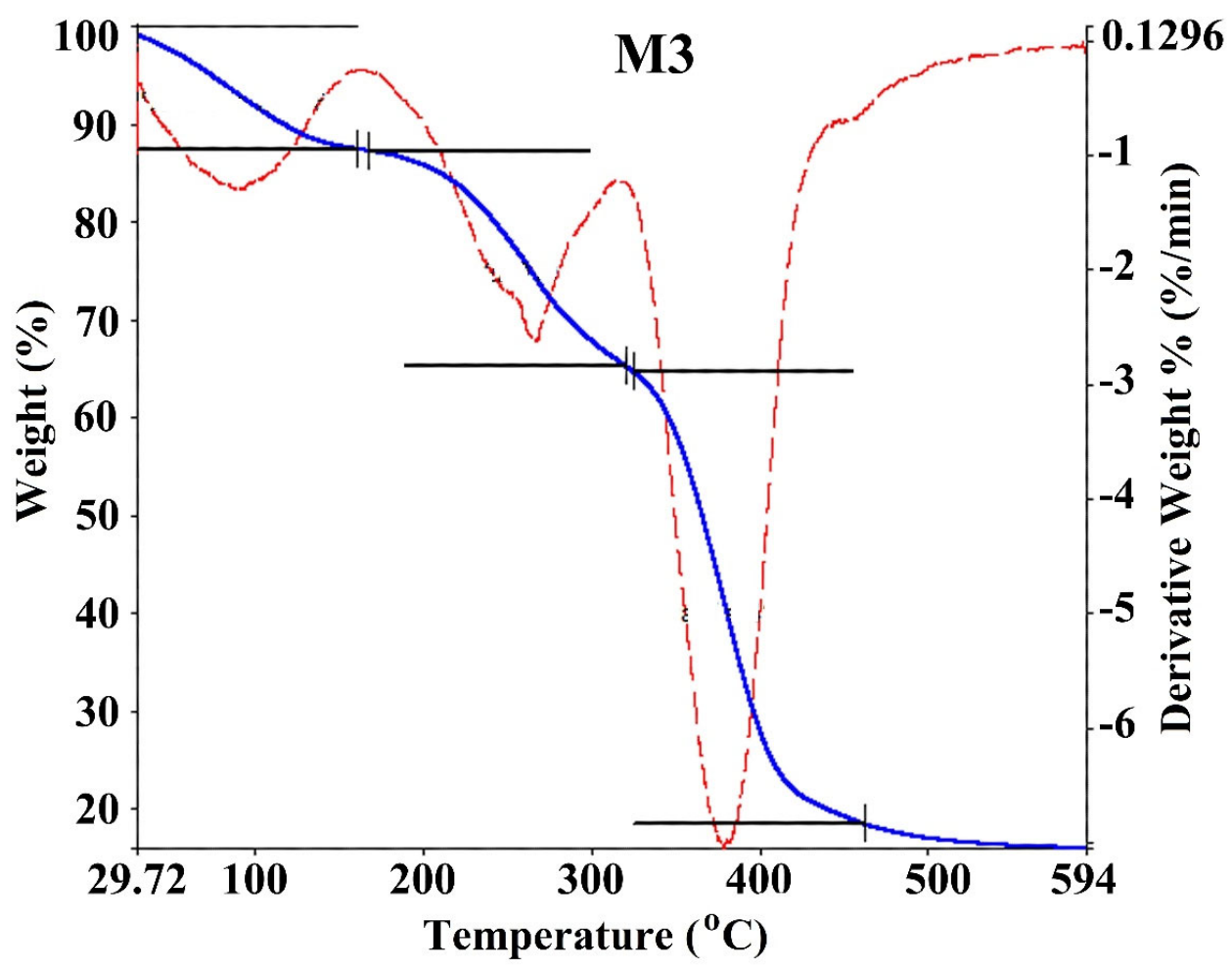

(a)

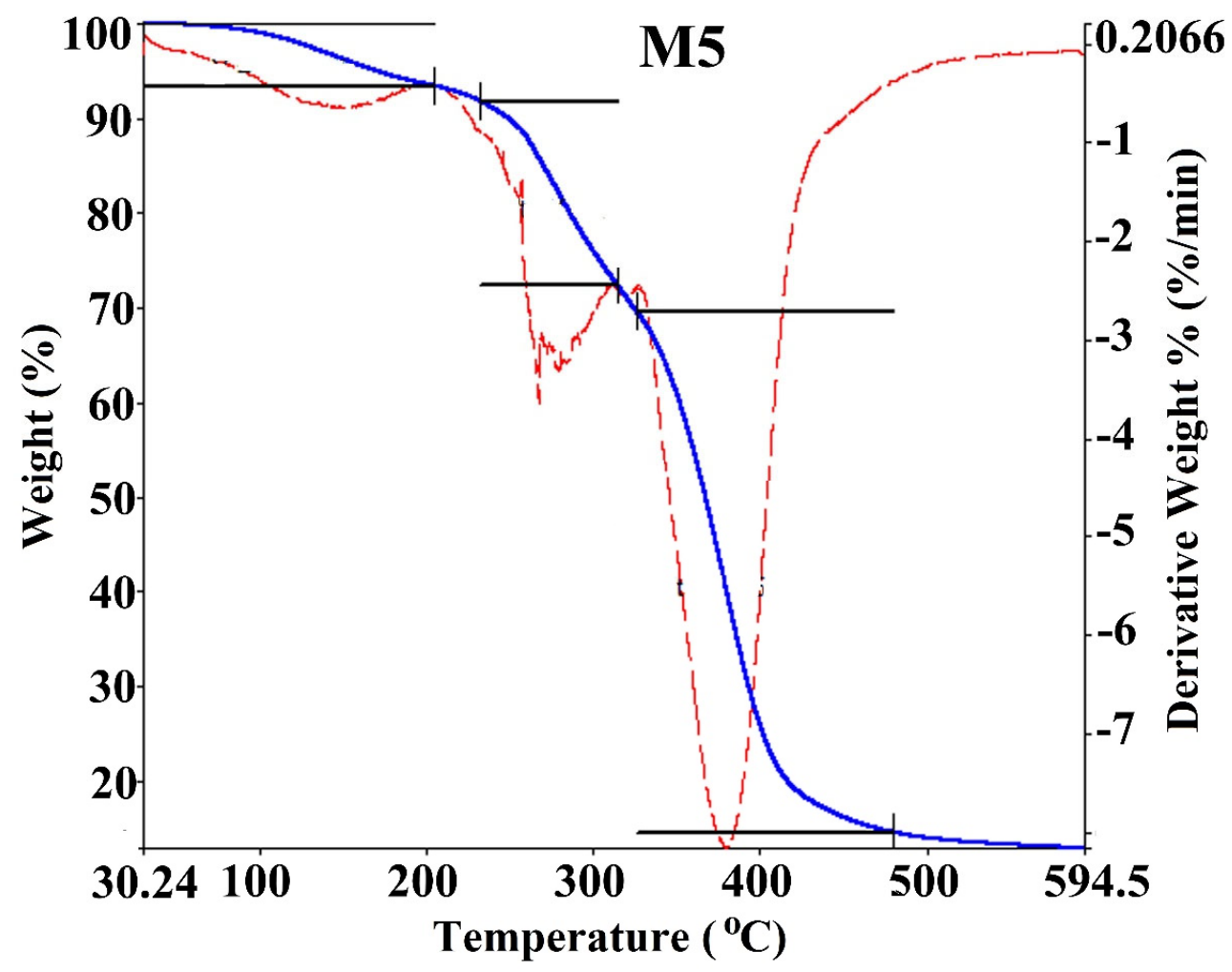

(b)

Figure 5. TGA curves of poly(DMA-co-AAc) hydrogel ((a) for M3 and (b) for M5). 
Table 3. Thermal properties of poly(DMA-co-AAc) hydrogels.

\begin{tabular}{ccccc}
\hline Copolymer & $\begin{array}{c}\text { Temperature Decomposition } \\
\left({ }^{\circ} \mathbf{C}\right)\end{array}$ & $\begin{array}{c}\text { Weight Loss } \\
\mathbf{( \% )}\end{array}$ & $\begin{array}{c}\text { Residual } \\
\mathbf{( \% )}\end{array}$ & $\begin{array}{c}\text { PDT }_{\max } \\
\left({ }^{\circ} \mathbf{C}\right)\end{array}$ \\
\hline \multirow{3}{*}{ M3 } & $29.72-160.31$ & 12.576 & 87.624 & \\
& $160.31-322$ & 22.424 & 65 & 380.92 \\
& $322-594$ & 49 & 16 & \\
M5 & $30.24-209.6$ & 6.76 & 93.24 & \\
& $209.6-317.36$ & 21.61 & 71.63 & 378.12 \\
\hline
\end{tabular}

\subsection{Scanning Electron Microscopy (SEM)}

One of the crucial properties of the hydrogels is their surface morphologies, which allow characterizing the properties and prospects of the copolymer for further research and applications. Figure 6 shows the SEM of poly(DMA-co-AAc) hydrogels (M3). The surface morphologies verify that the prepared hydrogels have three-dimensional porous structures. A three-dimensional structure might be a better cross-link of the hydrogel, and pores and permeable surfaces in hydrogels can increase swelling capacity. The interaction of water molecules with either hydrophilic groups or water permeation increases the hydrogel's porous structure that is the principal reason for the higher swelling ratios.
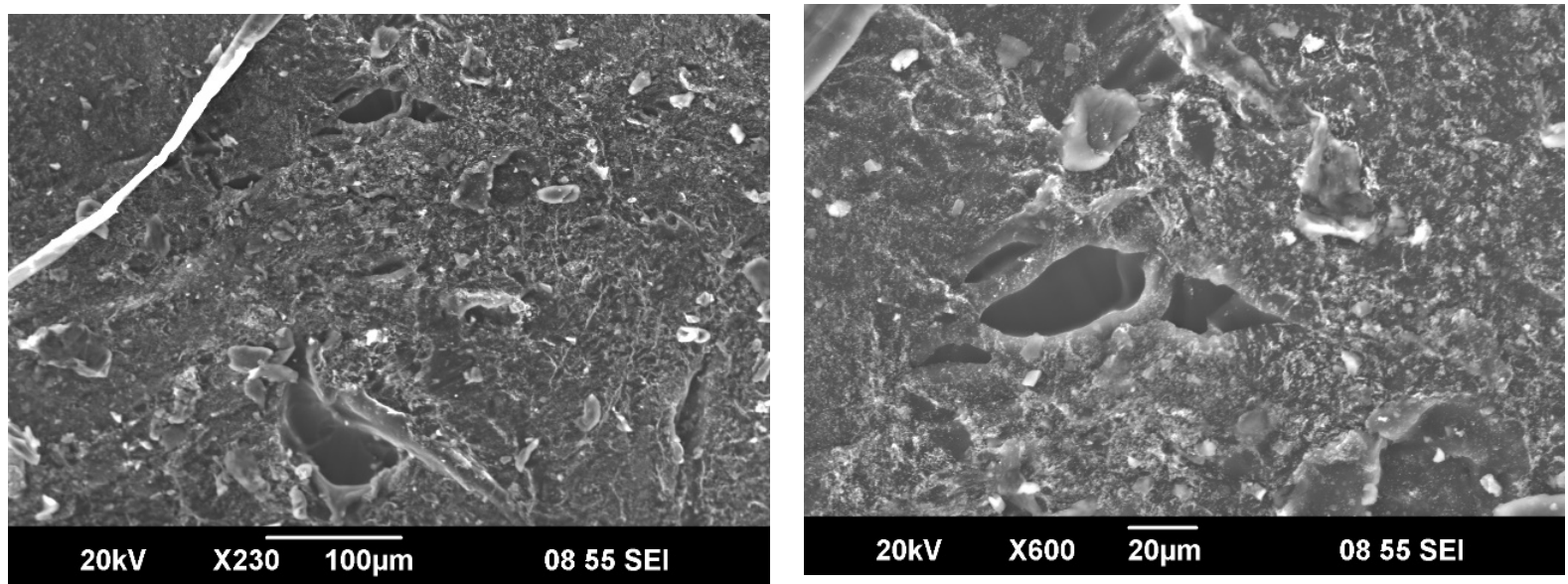

Figure 6. SEM Micrographs of poly(DMA-co-AAc) hydrogel (M3).

\subsection{Antibacterial Abilities of the Hydrogels Immobilized with the Drugs}

The antibacterial and drug delivery property of poly(DMA-co-AAc) hydrogels were evaluated, which might have the potential for biological applications and the use on surfaces for many applications and environments. GP bacteria [Staphylococcus aureus (ATCC 6538-p)] and two GN bacteria (E. coli (ATCC 25922) and P. aeruginosa (ATCC-9027)) were used for this purpose. Dry poly(DMA-co-AAc) hydrogels were immersed into gentamicin or water to absorb the liquid and the drug-free hydrogels were used as a control.

It was established that antibiotics diffused well into the medium from the carriers, inhibiting the test microorganism's growth and creating a lysis zone around the test carrier with antibiotics, indicating the drug delivery traits of the hydrogels, shown in Figures 7 and 8. Interestingly, a clear inhibition zone was also observed by hydrogels without antibiotic solutions, suggesting the antibacterial role of the hydrogels against GN bacteria E. coli and P. aeruginosa. However, the antibiotic-free poly(DMA-co-AAc) hydrogel did not show any remarkable bacteriostatic impact on the GP bacteria (ATCC 6538). In both cases, hydrogels with gentamicin showed promising results in suppressing bacterial growth, exhibiting a clear inhibition zone in GN and GP. This activity has the potential 
for important future applications, bearing in mind that high drug delivery ability with excellent antibacterial efficiency is a good feature for biological and medical applications.

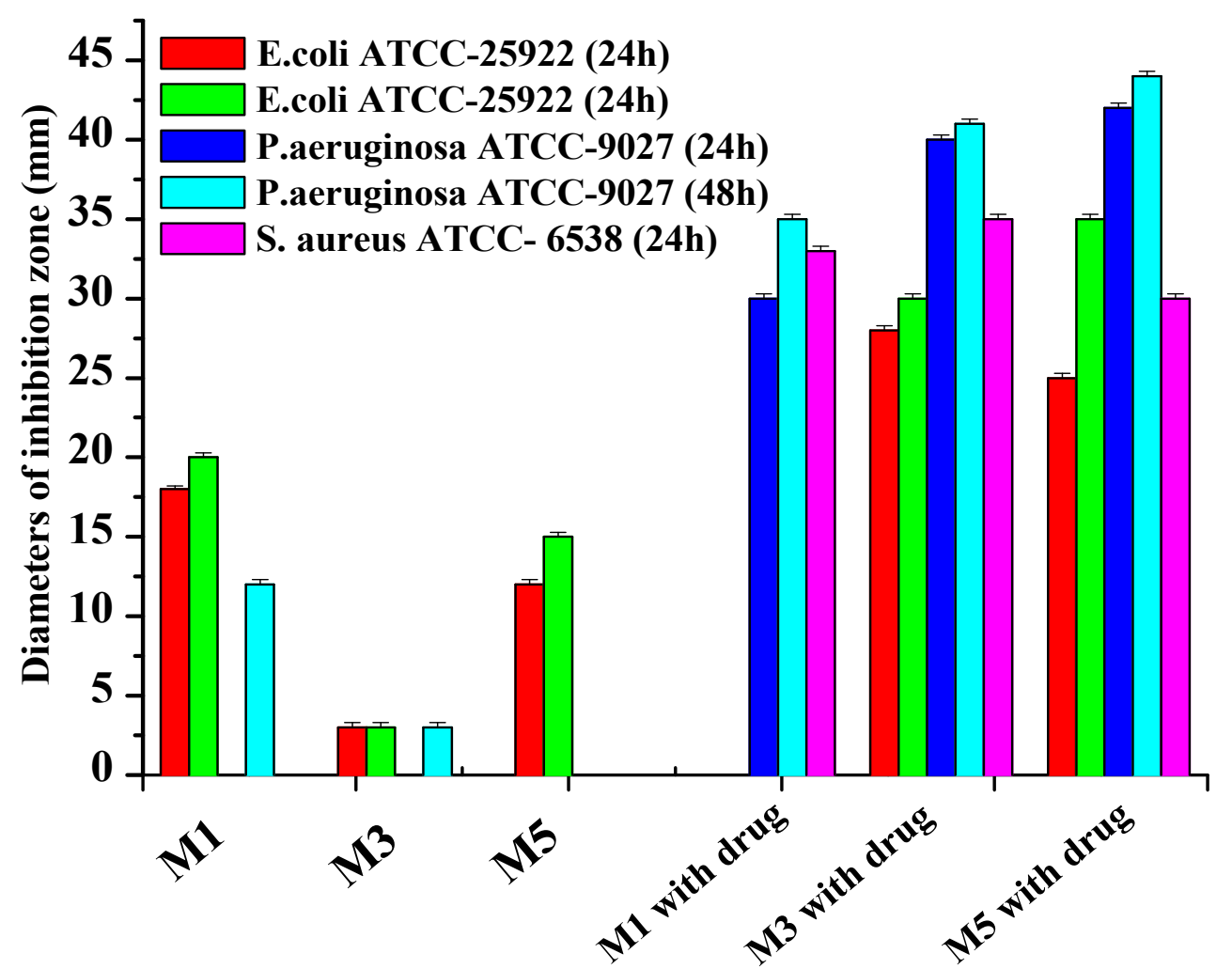

Figure 7. Inhibition zones of poly(DMA-co-AAc) hydrogels against GP (Staphylococcus aureus) and GN (E. coli and P. aeruginosa bacteria).

\section{P. aeruginosa ATCC-9027, $48 \mathrm{~h}$}
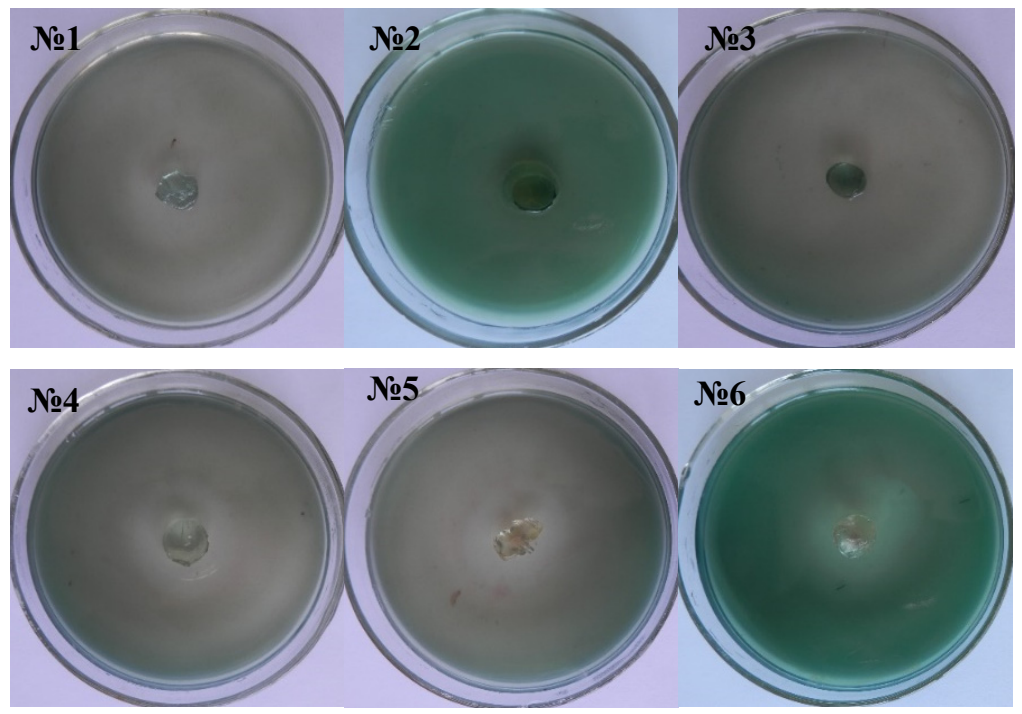

Figure 8. Cont. 


\section{E. coli ATCC25922, $48 \mathrm{~h}$}
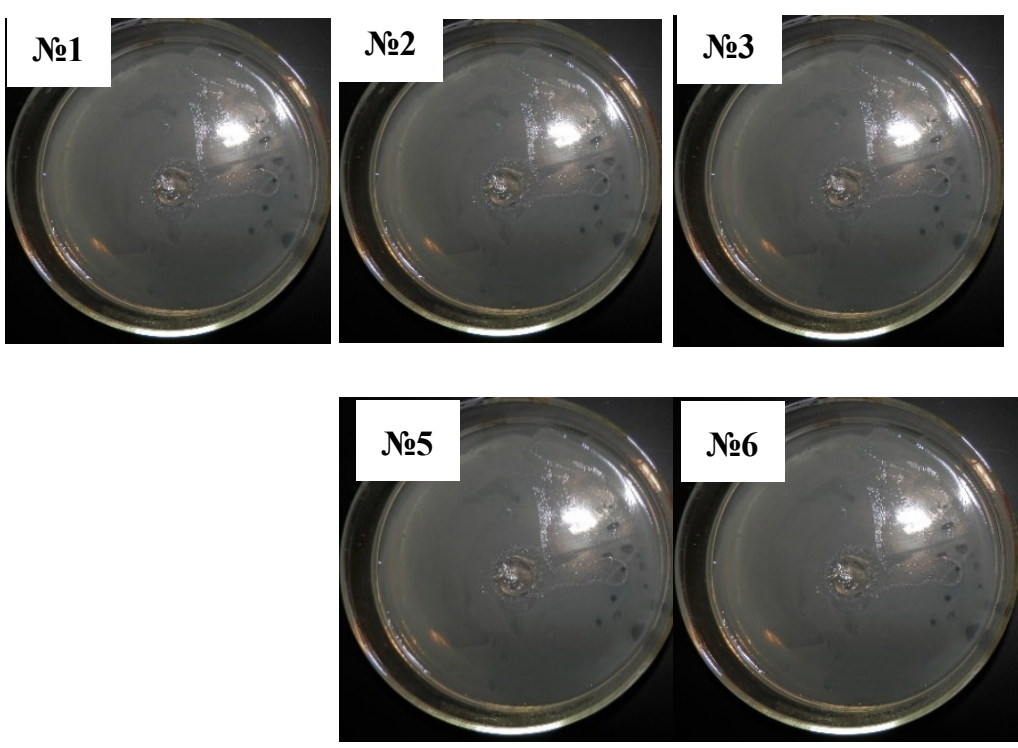

Staphylococcus aureus ATCC 6538-P, $48 \mathrm{~h}$
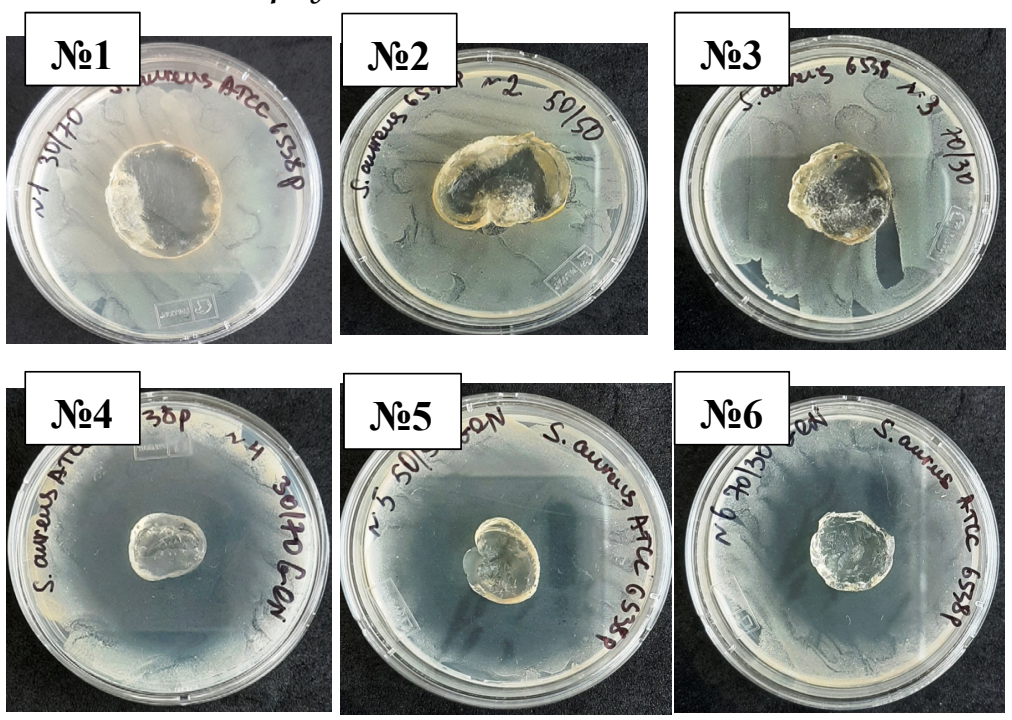

Figure 8. Antimicrobial activity of antibiotic-free and antibiotic-loaded poly(DMA-co-AAc) hydrogels against GP and GN bacteria (№ 1, 2, 3 for M1, M3, M5; № 4, 5, 6 for M 1, M3, M5 with gentamicin).

\section{Conclusions}

New poly(DMA-co-AAc) hydrogel was synthesized with different composition ratios of $\mathrm{N}, \mathrm{N}$-dimethyl acrylamide and acrylic acid by free-radical copolymerization using ammonium persulfate as an initiator. Different techniques have studied the physiochemical properties of hydrogel copolymer. TGA technique used to study the thermal stability of hydrogel copolymers. $\mathrm{CHN}$ was the main technique and linear methods to determine the copolymer composition and reactivity ratios Fineman-Ross $\left(\mathrm{r}_{1}=0.38 ; \mathrm{r}_{2}=1.45\right)$, inverted Fineman-Ross $\left(r_{1}=0.38 ; r_{2}=1.46\right)$, Kelen-Tudos $\left(r_{1}=0.38 ; r_{2}=1.43\right)$, and Mayo-Lewis $\left(r_{1}=0.38 ; r_{2}=1.45\right)$. As shown in the results, the calculated monomer reactivity ratios showed higher reactivity for AAc compared to DMA. Therefore, the growing radicals showed a higher tendency to react with AAc monomer due to the higher reactivity of AAc. SEM showed characteristics of poly(DMA-co-AAc) polymer network. poly(DMA-co-AAc) hydrogel without the addition of gentamicin did not show antibacterial activity against Staphylococcus aureus. poly(DMA-co-AAc) hydrogels with gentamicin showed an ability to inhibit the growth of Staphylococcus aureus. However, an increase in the molar ratio of 
DMA in the copolymer causes an increase in the ability of copolymer to reduce the growth of Staphylococcus aureus. Overall, future perspectives in developing safe and effective new hydrogels with drug delivery properties especially involving co-delivery of antimicrobial polymers and conventional antimicrobial agents for medical and hygienic applications.

Author Contributions: U.N. (Conceptualization, investigation, data curation, writing, editing, funding and project administration); S.B. and E.-S.N. (Preparation and editing); G.A.M. (Supervision and editing); K.T.; A.Y.; B.T. (Preparation, Methodology, formal analysis); M.A.; M.E.N. and R.K.R. (visualization, investigation, resources). All authors have read and agreed to the published version of the manuscript.

Funding: This study was supported by the Ministry of Education and Science of Kazakhstan, AP09562886 (2021). The authors are grateful for the Grant “Best Teacher of University, 2020" provided by Kazakhstan's Ministry of Education and Science.

Institutional Review Board Statement: Not applicable.

Informed Consent Statement: Not applicable.

Data Availability Statement: The data presented in this study are available on request from the corresponding author.

Acknowledgments: We appreciate Charlotte Volk (McGill University, Montreal, Quebec, Canada) for language editing in this article.

Conflicts of Interest: The authors declare no conflict of interest.

\section{References}

1. Osada, Y.; Ross-Murphy, S.B. Intelligent gels. Sci. Am. 1993, 5, 82-87. [CrossRef]

2. Hoffman, A.S. Hydrogels for biomedical applications. Adv. Drug Deliv. Rev. 2002, 54, 3-12. [CrossRef]

3. Qu, J.; Zhao, X.; Ma, P.X.; Guo, B. Injectable antibacterial conductive hydrogels with dual response to an electric field and pH for localized "smart" drug release. Acta Biomater. 2018, 72, 55-69. [CrossRef]

4. Mullarney, M.P.; Seery, T.; Weiss, R. Drug diffusion in hydrophobically modified N,N-dimethylacrylamide hydrogels. Polymer 2006, 47, 3845-3855. [CrossRef]

5. Mao, J.; Yu, Q.J.; Wang, S. Preparation of multifunctional hydrogels with pore channels using agarose sacrificial templates and its applications. Polym. Adv. Technol. 2021, 32, 1752-1762. [CrossRef]

6. Algi, M.P.; Okay, O. Highly stretchable self-healing poly(N,N-dimethylacrylamide) hydrogels. Eur. Polym. J. $2014,59,113-121$. [CrossRef]

7. Hernandez-Martíneza, A.R.; Lujan-Montelongo, J.A. Swelling and methylene blue adsorption of poly(N,N-dimethylacrylamideco-2-hydroxyethyl methacrylate) hydrogel. React. Funct. Polym. 2018, 122, 75-84. [CrossRef]

8. Yin, X.; Stover, H.D.H. Temperature-sensitive hydrogel microspheres formed by liquid-liquid phase transitions of aqueous solutions of Poly(N,N-dimethylacrylamide-co-allyl methacrylate). J. Polym. Sci. Part A Polym. Chem. 2005, 43, 1641-1648. [CrossRef]

9. Cheng, F.; Yi, J.; Ya, Z.; Zhong, L. Effect of N,N-dimethylacrylamide (DMA) on the comprehensive properties of acrylic latex pressure sensitive adhesives. Int. J. Adhes. Adhes. 2016, 71, 105-111. [CrossRef]

10. Polic, A.L.; Duever, T.A.; Penlidis, A. Case studies and literature review on the estimation of copolymerization reactivity ratios. J. Polym. Sci. Part A Polym. Chem. 1998, 36, 813-822. [CrossRef]

11. Biryan, F.; Demirelli, K. Copolymerization of benzyl methacrylate and a methacrylate bearing benzophenoxy and hydroxyl side groups: Monomer reactivity ratios, thermal studies and dielectric measurements. Fibers Polym. 2017, 18, 1629-1637. [CrossRef]

12. Rusu, L.-C.; Ardelean, L.C.; Jitariu, A.-A.; Miu, C.A.; Streian, C.G. An Insight into the Structural Diversity and Clinical Applicability of Polyurethanes in Biomedicine. Polymers 2020, 12, 1197. [CrossRef] [PubMed]

13. Takeuchi, M.T.; Kojima, M.; Luetzow, M. State of the art on the initiatives and activities relevant to risk assessment and risk management of nanotechnologies in the food and agriculture sectors. Food Res. Int. 2014, 64, 976-981. [CrossRef]

14. Nakan, U.; Rahmetullaeva, K.R.; Mun, G.A.; Shaihutdinov, E.M.; El-Sayed, N. Linear Copolymer of N-Isopropylacrylamide and 2-Hydroxyethylacrylate: Synthesis, Characterization and Monomer Reactivity Ratios. Orient. J. Chem. 2016, 32, 2347-2354. [CrossRef]

15. Nakan, U.; Mun, G.A.; Shaikhutdinov, E.M.; Bieerkehazhi, S.; El-Sayed, N. Hydrogels based on N-isopropylacrylamide and 2-hydroxyethylacrylate: Synthesis, characterization and investigation of their antibacterial activity. Polym. Int. 2020, 69, 1220-1226. [CrossRef]

16. Nakan, U.; Mun, G.A. Thermosensitive N-isopropylacrylamide -co-2-hydroxyethyl acrylate hydrogels interactions with Poly(acrylic acid) and surfactants. Polym. Adv. Technol. 2021, 32, 2676-2681. [CrossRef] 
17. Nakan, U.; Rahmetullayeva, R.K.; Mun, G.A. Synthesis of water soluble copolymers and their interpolymer complexes with Poly(acrylic acid). J. Chem. Technol. Metall. 2018, 53, 183-187.

18. Abdollahi, H.; Najafi, V.; Amiri, F. Determination of monomer reactivity ratios and thermal properties of poly(GMA-co-MMA) copolymers. Polym. Bull. 2021, 78, 493-511. [CrossRef]

19. Fineman, M.; Ross, S.D. Linear method for determining monomer reactivity ratios in copolymerization. J. Polym. Sci. 1950, 5, 259-265. [CrossRef]

20. Kelen, T.; Tüdös, F. Analysis of the linear methods for determining the copolymerization reactivity ratios I. A new improved linear graphic method. J. Macromol. Sci. Part A Pure Appl. Chem. 1975, 9, 1-27. [CrossRef]

21. Mayo, F.R.; Lewis, F.M. Copolymerization. I. A Basis for Comparing the Behavior of Monomers in Copolymerization; The Copolymerization of Styrene and Methyl Methacrylate. J. Am. Chem. Soc. 1944, 66, 1594-1601. [CrossRef]

22. Bhattacharyya, R.; Ray, S.K. Enhanced adsorption of synthetic dyes from aqueous solution by a semi-interpenetrating network hydrogel based on starch. J. Ind. Eng. Chem. 2014, 20, 3714-3725. [CrossRef]

23. Hai, A.F.; Wahab, H.A.; Ibrahim, A. Synthesis, characterization and thermal properties of thiazole containing polymers. Malays Polym. J. 2014, 9, 1-9.

24. Sadeghi, M.; Hanifpour, F.; Taheri, R.; Javadian, H.; Ghasemi, M. Comparison of us-ing formaldehyde and carboxy methyl chitosan in preparation of $\mathrm{Fe}_{3} \mathrm{O}_{4}$ superpara-magnetic nanoparticles-chitosan hydrogel network: Sorption behavior toward bo-vine serum albumin. Process Saf. Environ. 2016, 102, 119-128. [CrossRef]

25. Moharram, M.A.; Khafagi, M.G. Thermal behavior of Poly(acrylic acid)-Poly(vinylpyrrolidone) and Poly(acrylic acid)-metalPoly(vinylpyrrolidone) complexes. J. Appl. Polym. Sci. 2006, 102, 4049-4057. [CrossRef] 